\title{
Rompendo o Paradigma Estratégico-Realista: por uma Perspectiva Epistemológica Eclética dos Estudos de Defesa
}

\author{
Breaking the Strategic-Realist Paradigm: \\ for an Eclectic Epistemological Perspective \\ of Defense Studies
}

GILBERTO CARVALHO DE OLIVEIRA

\section{INTRODUÇÃO}

Subjacente à questão sobre "como a defesa deve ser estudada", colocada em debate nesta edição especial da RBED, encontra-se um importante "problema de demarcação": ${ }^{1}$ dentro de uma emergente área de estudos de defesa, que se propõe afirmar como conhecimento científico, que critérios permitem demarcar a fronteira entre uma ciência da defesa e uma doutrina da defesa? Mais importante ainda: considerando o que fica dentro dos limites científicos da defesa, como os pesquisadores devem conhecer o seu objeto de estudo? No atual contexto acadêmico brasileiro, onde se observa a emergência de programas de graduação e pós-graduação dedicados ao estudo da defesa, acompanhado de um movimento em prol da institucionalização da defesa como área de pesquisa científica, essas questões epistemológicas adquirem especial relevância.

A preocupação científica com o estudo da guerra - e com os seus desdobramentos no domínio da defesa nacional e da segurança internacional - não é particularmente nova. A estratégia, com o seu foco conceptual centrado na relação entre guerra e política, procurou articular-se como conhecimento científico, principalmente a partir da influência marcante da teoria da guerra de Clausewitz e da sua crescente familiarização com os métodos científicos (positivismo, quantificação, teoria dos jogos) ainda no decorrer da primeira metade do século XX. Nas décadas seguintes ao fim da Segunda Guerra Mundial, dentro de um quadro fortemente condicio-

Gilberto Carvalho Oliveira - Doutor em Relações Internacionais (Universidade de Coimbra) e professor de Relações Internacionais (UFRJ). E-mail: gilbertooliv@gmail.com. 
nado pelas dinâmicas políticas próprias da Guerra Fria, pelo imperativo tecnológico nuclear e pela institucionalização da estratégia como agenda de investigação "legítima" no estudo da segurança internacional, principalmente nos Estados Unidos, os estudos estratégicos e a abordagem realista das Relações Internacionais encontraram as condições propícias para uma aproximação. Com o campo disciplinar das Relações Internacionais mergulhado no seu "segundo grande debate" - onde a disputa "tradicionalismo-cientificismo" substituía a disputa "realismo-idealismo" que marcara o nascimento da disciplina -, as afinidades entre a estratégia e o realismo, até então limitadas a uma convergência conceptual em torno de noções basilares como as de sobrevivência, poder e interesse nacional, ${ }^{2}$ passavam a ser marcadas, também, por uma convergência acadêmico-científica-institucional (BUZAN e HANSEN, 2009, p. 66-100).

Com essa aliança estabelecida ao longo da Guerra Fria, consolida-se no domínio das Relações Internacionais uma perspectiva racionalista/neopositivista $^{3}$ da segurança internacional, que se pode rotular de "paradigma estratégico-realista” (OLIVEIRA, 2015a, 2015b), contra o qual passam a se posicionar as abordagens constitutivas/pós-positivistas (orientadas por um viés construtivista social e compostas por uma variedade de teorias sociais como a teoria crítica, o pós-estruturalismo, o feminismo, etc.). Perante a incapacidade dos estrategistas e realistas de anteverem o fim da Guerra Fria e de explicarem o seu desfecho pacífico, apesar de todo o aparato explanatório neopositivista desenvolvido para produzir generalizações e previsões sobre as interações estratégicas entre as duas superpotências, as abordagens constitutivas/pós-positivistas emergem com o claro objetivo de desafiar a epistemologia causal que está na base do paradigma estratégico-realista (FIERKE, 2005, p. 13). Assumindo a dificuldade de conhecer a política internacional em sua materialidade e de explicar a relação entre guerra e política através da identificação de relações causais objetivamente observáveis e generalizáveis (tal como prevalece no paradigma estratégico-realista), as abordagens constitutivas/pós-positivistas passam a defender novas lentes para a compreensão e o estudo das questões de segurança. Conforme argumentam Krause e Williams (1997, p. 49-50), esse movimento produz um salto epistemológico para além do objetivismo e do racionalismo predominantes nos estudos estratégicos e no realismo, a fim de alcançar um modo mais reflexivo e interpretativo de análise que amplie o foco dos estudos de segurança para além das preocupações com as capacidades militares e as interações estratégicas dos Estados. Através desse salto, todo o arcabouço de ideias, instituições e instrumentos de violência centrado no Estado, no conceito de soberania e nas noções de segurança, defesa e interesse nacional passa a ser "desnaturalizado" e questionado em 
suas pretensões de universalidade. Dentro desse quadro, a problemática da segurança amplia-se, passando a ser vista como resultado de práticas sociais historicamente situadas e a ser equacionada através de um leque de novas preocupações: a construção social de identidades e suas conexões com as comunidades e a cultura; o papel das ideias, normas e valores na constituição do que precisa ser defendido e colocado em segurança; a ampliação das percepções sobre o que são as ameaças de segurança; a compreensão sobre o processo discursivo de construção dessas ameaças; a possibilidade de transformação das práticas e concepções de segurança através da reflexão crítica; a compreensão sobre as questões de gênero envolvidas nas relações sociais que moldam as práticas de segurança; as marginalizações, invisibilidades e silenciamentos produzidos pelos discursos e práticas da segurança; etc. A partir desse movimento de expansão, consolida-se no domínio disciplinar das Relações Internacionais o subcampo dos "estudos de segurança internacional”, que passa a ser visto como um grande rótulo guarda-chuva, como um grande título organizador que engloba não só as abordagens constitutivas/pós-positivistas, geralmente abrigadas sob o subtítulo de "estudos críticos de segurança", mas também a tradicional abordagem do paradigma estratégico-realista, que passa a ser vista como uma entre tantas outras abordagens que tentam disputar espaço na compreensão da segurança internacional.

Perante esse panorama, o ponto crucial a notar para os propósitos deste artigo é que, apesar da expansão do quadro de referência dos estudos de segurança internacional, o paradigma estratégico-realista - com a epistemologia causal que determina a sua orientação racionalista/neopositivista - continua a ser a perspectiva dominante, a partir da qual as questões de segurança e defesa são examinadas. Se isto é um fato evidente no contexto acadêmico norte-americano, onde predomina uma rígida concepção neopositivista sobre o significado de se produzir teoria, e um pouco menos óbvio no contexto acadêmico europeu, onde se observa uma epistemologia reflexiva mais suave sobre a produção teórica (WÆVER, 1998), é possível notar no contexto brasileiro, entre os acadêmicos que assumem explicitamente um compromisso com o estudo científico da defesa, o predomínio da orientação racionalista/neopositivista típica do paradigma estratégico-realista. Uma ilustração emblemática dessa perspectiva pode ser observada no tex to de Proença Jr. e Duarte (2007), intitulado Os estudos estratégicos como base reflexiva da defesa nacional, onde os autores condicionam a produção de conhecimento científico na área da defesa à sua conexão necessária com o legado dos estudos estratégicos, sobretudo com a teoria da guerra de Clausewitz."

$\mathrm{O}$ argumento central deste artigo é que, embora o paradigma estratégico/realista ofereça uma via plausível para orientar as pretensões de 
cientificidade dos estudos de defesa, essa via oferece uma perspectiva epistemológica unidimensional - que reproduz o mito da superioridade racionalista/neopositivista da ciência - sem considerar alguns desenvolvimentos epistemológicos alternativos importantes ocorridos na filosofia da ciência. Desse modo, procurando ir além do paradigma estratégico-realista dominante, este artigo pretende explorar uma base epistemológica mais diversificada que seja compatível com o estudo da complexidade e da variedade dos fatores e questões que influenciam o processo de construção social da agenda de defesa no Brasil e no mundo. Para atingir esse propósito, o artigo segue organizado em quatro seções. A primeira seção expande o exame do que foi anteriormente chamado de "problema de demarcação", procurando desfazer algumas confusões verificadas no debate "cientificamente mal informado”, em geral guiado por visões do senso comum ou por interesses instrumentais, que tende a ver a defesa de um ponto de vista fixo e unificado e a ancorar o "problema da demarcação" nas doutrinas e documentos orientadores das burocracias de defesa do Estado. A seção seguinte procura examinar de que forma o mainstrean acadêmico brasileiro dedicado às questões de defesa tenta distanciar-se desse senso comum, justificando a base científica dos estudos de defesa a partir dos estudos estratégicos. Reconhecendo que esse é um caminho legítimo, mas reconhecendo ao mesmo tempo que existem outras vias para o conhecimento científico, a última seção busca no trabalho de Patrick Jackson (2011), centrado na filosofia da ciência, uma base epistemológica mais diversificada para justificar o estudo científico da defesa. Concluindo, discutem-se os aspectos examinados no artigo e avalia-se até que ponto uma epistemologia pluralista constitui uma proposta consistente para os estudos de defesa.

\section{A “COMUNIDADE DE DEFESA” E O “PROBLEMA DA DEMARCAÇÃO”}

Ao examinar o nascimento e a consolidação das Relações Internacionais no Brasil, Lima (2015) observa que esse processo foi fortemente marcado pela tutela do Estado e pelo esforço de treinar profissionais tecnicamente qualificados para atuar no projeto estatal de inserção internacional do Brasil; desse modo, em vez da promoção da pesquisa científica, o início da institucionalização da disciplina na década de 1970 teve o objetivo maior de "produzir técnicos" capazes de ajudar as burocracias do estado na interface interna-externa na era do "Brasil Potência". Essa certidão de nascimento tem, segundo a autora, consequências que perduram até hoje. Uma delas é que a disciplina continua autocentrada, dedicada primordialmente à inserção internacional do Brasil, e pouco dedicada à teorização do internacional propriamente dito. Outra consequência é que o campo das Relações 
Internacionais (RI) se constituiu em torno de uma "comunidade de RI", onde o esforço acadêmico independente, dedicado à pesquisa e à teorização, convive lado a lado com militares, diplomatas, jornalistas e alguns políticos que também se integram a essa "comunidade", partindo da assunção de que o conhecimento empírico relevante não depende necessariamente de teoria; em consequência, observa Lima, "ideias do senso-comum estruturadas sob uma forma acadêmica” passam a disputar espaço com a produção científica na área (LIMA, 2015, p. 107-145).

É interessante notar, transferindo o foco para a nascente área de estudos de defesa, que algumas dinâmicas semelhantes se repetem. Existe uma "comunidade de defesa" que vai além do âmbito acadêmico-científico propriamente dito e coloca, ao lado de pesquisadores, um grupo de militares, diplomatas, jornalistas e políticos que, com base na sua experiência e conhecimento especializado sobre a operação das burocracias do Estado, produzem uma reflexão centrada nas questões pragmáticas e instrumentais da defesa, em detrimento das preocupações teóricas ou de uma reflexão alternativa que saia do círculo vicioso em torno do projeto estatal de inserção internacional do Brasil. Os ciclos de debates orquestrados pelo Ministério da Defesa em 2003, que resultaram nos volumes que compõem a publicação Pensamento brasileiro sobre defesa e segurança (PINTO et al., 2004), ilustram claramente essa composição diversificada da "comunidade de defesa" e mostram que o seu foco central de preocupações se dirige mais às questões instrumentais da inserção internacional do país do que às questões de teorização da defesa. Desse modo, ainda que as iniciativas de debate no seio dessa "comunidade de defesa" sejam louváveis do ponto de vista político, sob o argumento de que elas favorecem a troca democrática de ideias, isto não muda o fato de que interessa às burocracias da defesa, em última análise, atrair o setor acadêmico para compor o esforço estatal de inserção internacional na área de defesa, para não falar aqui de interesses ainda mais específicos das corporações militares que levam a uma aproximação seletiva ao meio acadêmico com base no que interessa/ não interessa para as forças armadas (NETO, 2014, p. 216). Se isto não parece problemático do ponto de vista político, o mesmo não pode ser dito quando se pensa na defesa do ponto de vista da produção de conhecimento teórico-científico.

Sobre essa fronteira entre o político-institucional e o científico na produção de conhecimento sobre a defesa, é importante desfazer algumas confusões verificadas no debate, em geral guiado por visões do senso comum ou por interesses instrumentais, que eventualmente prolifera no âmbito da "comunidade de defesa". Antes de tudo, é crucial compreender que uma coisa é a defesa enquanto instituição política burocrática, outra coisa 
é a defesa enquanto campo de conhecimento, enquanto área disciplinar, enquanto agenda de pesquisa científica. Essas duas instâncias nutrem-se uma da outra, mas não se confundem e nem se correspondem univocamente. Se do lado político-institucional, a defesa tem o seu foco centrado nas estruturas, na capacitação e no estabelecimento de doutrinas que permitam a padronização de conhecimentos e a aplicação racionalizada do instrumento militar - e não há nada de errado nisto se considerarmos as suas características funcionais e os seus propósitos político-burocráticos -, de outro lado, é preciso compreender que a defesa enquanto área de estudos não se condiciona pelo pensamento e pelas práticas especializadas próprias desse campo institucional. A produção de conhecimento científico deve ser absolutamente independente e o campo disciplinar da defesa não nasce por imposições ou orientações doutrinárias emanadas da esfera político-institucional. ${ }^{5}$

Da perspectiva da produção de conhecimento, portanto, "o problema da demarcação" (o que fica dentro e o que fica fora do conhecimento científico sobre a defesa) não se resolve com base nas doutrinas, nos dicionários ou nos documentos e políticas públicas da defesa, mas se resolve no âmbito das dinâmicas próprias da investigação acadêmica, das agendas dos pesquisadores envolvidos na produção de conhecimento científico sobre o tema, na produção de teorias que tentam descrever, explicar ou criticar as práticas político-institucionais da defesa, admitindo-se, inclusive, a proposição de conceitos e teorias que rompam radicalmente com o que é doutrinariamente definido por defesa. Por exemplo, nada impede que um pesquisador estude a defesa por civis e o transarmamento ${ }^{6}$ ou investigue o modelo pacifista adotado pela Costa Rica (onde as forças armadas foram abolidas há mais de 50 anos), enquadrando essas agendas dentro do rótulo de estudos de defesa. Nada impede, igualmente, que um pesquisador examine os níveis de violência armada produzidos pela criminalidade urbana e a percepção dessa ameaça pela sociedade, a fim de analisar as implicações dessas dinâmicas internas na construção social da agenda da defesa. Ainda que do ponto vista especializado das chamadas "ciências militares" e dos documentos orientadores das burocracias de defesa (política, estratégia e doutrina), essas agendas alternativas possam parecer conceptualmente questionáveis, isto não significa que elas não constituam objetos de pesquisa legítimos e não possam ser consistentemente elaboradas do ponto de vista teórico na agenda dos estudos de defesa.

Uma segunda confusão a ser desfeita é a ideia de que a expansão da agenda de segurança e defesa tem uma origem exclusiva na área acadêmica, introduzindo no debate sobre o tema inconsistências conceptuais produzidas por "não especialistas". É importante perceber que essa expansão 
conceptual (através da inclusão de questões ligadas à criminalidade urbana, ao meio ambiente, às atividades cibernéticas, às epidemias, às migrações, ao subdesenvolvimento, aos direitos humanos ou às operações de paz, por exemplo) nasce de securitizações ocorridas na esfera política, aceitas não só pela sociedade (que percebe essas ameaças como mais prioritárias do que as tradicionais ameaças militares externas), mas também pelas próprias burocracias de defesa que, por uma série de fatores como a disputa por orçamentos públicos, busca de reconhecimento social, prestígio internacional, oportunidades de emprego da força em situações reais, remunerações adicionais para os militares, etc., acabam legitimando e reforçando os movimentos de securitização que expandem as fronteiras da defesa para além da sua dimensão convencional. O que os pesquisadores fazem, perante esse quadro, é observar ou interpretar essas dinâmicas, que são próprias do mundo político, testando teorias explanatórias ou construindo teorias críticas ou modelos de análise, muito antes que as burocracias de defesa, geralmente conservadoras e presas ao status quo, reconheçam e introduzam essas mudanças conceptuais em suas doutrinas.

A principal consequência dessa falta de demarcação entre o científico e o político/doutrinário dentro dessa "comunidade de defesa" é a geração de um déficit na teorização em favor de um excedente de relatos descritivos, comentários, opiniões valorativas, análises de conjuntura, resenhas políticas, panfletos de justificação dos interesses das burocracias de defesa que, embora estruturados sob a forma de artigos acadêmicos, não revelam qualquer preocupação teórica e, muito menos, algum tipo de conhecimento ou interesse pelas questões epistemológicas e metodológicas envolvidas no estudo científico do tema, dentro do grau de profundidade necessário.

\section{O PARADIGMA ESTRATÉGICO-REALISTA COMO BASE CIENTÍFICA DOS ESTUDOS DE DEFESA}

Alguns acadêmicos brasileiros têm-se dedicado, há algum tempo, a distanciar-se do senso comum e dos limites doutrinários e a buscar uma resposta científica para esse "problema de demarcação" no estudo das questões de defesa ${ }^{7}$ adotando como critério de cientificidade os estudos estratégicos. No "Guia de Estudos Estratégicos", que resulta da colaboração entre a Escola de Guerra Naval (EGN) e o Grupo de Estudos Estratégicos da Coordenação dos Programas de Pós-Graduação em Engenharia da Universidade Federal do Rio de Janeiro (GEE-COPPE/UFRJ), seus autores salientam, na introdução, "que o texto foi produzido com total liberdade acadêmica, não devendo ser visto como doutrina ou qualquer manifestação oficial do pensamento da Marinha do Brasil” (PROENÇA JR., 
DINIZ e RAZA, 1999, p. 14). Se esse guia demonstra o esforço dos autores para apresentar a estratégia como uma base científica para a análise das questões da guerra e da defesa, distanciando-se, desse modo, dos aspectos doutrinários associados a esses temas, os seus esforços subsequentes dão sinais ainda mais claros e contundentes de como essa conexão entre a estratégia e a defesa (algumas vezes amparada num terceiro pilar derivado das teorias realistas das Relações Internacionais) deve ser reforçada como uma via consistente para demarcar a fronteira entre o que pode e não pode ser considerado conhecimento científico nos estudos da guerra e da defesa (RAZA, 2000, 2004; PROENÇA JR., 2004; PROENÇA JR. e DUARTE, 2007; DINIZ, 2010).

Nesse esforço de buscar uma fundação científica para os estudos de defesa dentro dos estudos estratégicos - ou dentro do que chamamos anteriormente de paradigma estratégico-realista - três aspectos são particularmente relevantes para os efeitos deste artigo. Em primeiro lugar, é preciso ter em conta que esse movimento implica em trazer para os estudos de defesa a epistemologia causal que está na base do paradigma estratégico-realista, juntamente com o seu aparato metodológico racionalista/neopositivista (quantificação, análises estatísticas, teoria dos jogos, modelos formais, escolha racional, etc.). O paradigma estratégico-realista parte da perspectiva científica dominante, derivada das ciências da natureza, sobre a forma como o pesquisador deve se posicionar para conhecer o seu objeto de estudo: observar objetivamente a realidade, a fim de identificar relações de causa e efeito, com base em evidências empíricas, que possam levar a uma lei, a um modelo, a uma generalização que, por sua vez, possibilite uma previsão. Em última análise, é isto que o paradigma estratégico-realista procura, do ponto de vista da produção de conhecimento científico: estabelecer generalizações sobre a forma como o poder militar se converte em poder político, a partir da observação de relações de causa-efeito, evidentes e necessárias, comprovadas através de hipóteses empiricamente testadas, que permitam prever o comportamento dos atores em suas interações estratégicas. Seguindo a tradição filosófico-científica de Popper, esse é um movimento permanente, que se sucede indefinidamente, até que uma dada presunção de verdade seja enfim "falsificada". Dessa perspectiva epistemológica, não existem verdades definitivas na ciência, existem verdades provisórias que ainda não foram comprovadas como falsas. Alguns textos-chave que propõem a articulação entre estudos de estratégia e estudos de defesa, embora sem usar necessariamente os termos aqui empregados, reproduzem claramente essa lógica neopositivista popperiana como a base do conhecimento cientificamente válido (PROENÇA JR. et al., 1999, p. 27-30; PROENÇA JR., 2004, p. 94-99). Ao trazer essa perspectiva para os 
estudos de defesa, isto significa, portanto, que a resposta à questão "como a defesa deve ser estudada" tenha que ser respondida, do ponto de vista epistemológico, da seguinte forma: através da observação objetiva da realidade, buscando formular e testar hipóteses que permitam "comprovar" ou "falsificar" as reivindicações gerais de verdade, através da confrontação com as evidências empíricas.

Em segundo lugar, é crucial perceber que essa presunção de cientificidade não se transfere de forma automática e nem se justifica ao nível meramente retórico. A proposição "a estratégia é um conhecimento científico, logo o estudo da defesa também se torna científico se usar a estratégia como base” é falaciosa se as implicações epistemológicas e metodológicas aí envolvidas não forem levadas a sério. Para tornar essa proposição consistente, é preciso que os estudos de defesa formulem novas hipóteses ou derivem hipóteses a partir do arcabouço teórico que compõe o paradigma estratégico-realista (teoria da guerra, teoria da balança de poder, teoria da dissuasão, dilema de segurança, teoria do balanço ataque-defesa, etc.) e que essas hipóteses sejam empiricamente testadas nas agendas de pesquisa dos estudos de defesa. Ainda que se deva reconhecer que esses aspectos têm sido considerados pelos autores referidos nesta seção e que essas questões tendem a se desenvolver com a proliferação das pós-graduações e da pesquisa científica na área de defesa e estratégia no país, deve-se igualmente reconhecer que muito do que se tem produzido dentro do que chamamos de "comunidade de defesa", conforme discutiu-se na seção anterior, revela uma completa despreocupação com as implicações epistemológicas e metodológicas envolvidas na produção do conhecimento científico.

Em terceiro lugar - e talvez aqui resida o desafio mais importante no debate epistemológico sobre os estudos de defesa - é importante reconhecer que o conhecimento científico não se resume ao tipo de epistemologia causal examinado nesta seção. Embora essa epistemologia constitua a abordagem dominante, ao ponto de ser defendida como a única via neutra e segura para o conhecimento científico, ela não é a única forma através da qual o pesquisador se posiciona em relação ao objeto do conhecimento e nem é a única forma através da qual o conhecimento se relaciona com a observação. Ainda que esse tipo de discussão metateórica ${ }^{8}$ pareça árido e abstrato para a grande parte dos estudantes e pesquisadores, geralmente pressionados pelas preocupações mais práticas e urgentes da pesquisa acadêmica, esse debate tem implicações cruciais para a reflexão proposta neste artigo. Tomando por base o extenso trabalho sobre filosofia da ciência realizado por Jackson (2011), a próxima seção procura destacar alguns elementos que permitam conceber o conhecimento científico de uma perspectiva epistemológica mais diversificada. 


\section{PARA ALÉM DO DUALISMO FENOMENALISTA ${ }^{9}$}

A epistemologia causal que está na base do paradigma estratégico-realista, que na verdade traz para o estudo dos fenômenos sociais os mesmos pressupostos aplicados ao estudo dos fenômenos da natureza, considera que a validação do conhecimento só pode ser realizada através da formulação e do teste de hipóteses com base na identificação de correlações causais, necessárias e empiricamente observáveis, que indiquem regularidades ou generalizações. Dentro do paradigma estratégico-realista, essa é a única perspectiva epistemológica capaz de levar a uma produção teórica neutra, objetiva, despida de juízos de valor, capaz de retratar a realidade tal como ela é e, por esse conjunto de razões, a única via para a produção científica na área. Embora essa perspectiva sobre a validade do conhecimento científico pareça óbvia, natural e incontestada - e é isso que a torna dominante -, é importante compreender que ela só faz sentido a partir da combinação de dois pressupostos epistemológicos específicos. Em primeiro lugar, o pressuposto "dualista”, cartesiano, de que o mundo é independente da mente do investigador. Esta separação entre o sujeito e o objeto do conhecimento, que marca todo o desenvolvimento da ciência moderna, leva à necessidade imperiosa de sucessivos testes empíricos de hipóteses como única forma "segura" - ou seja, livre do risco de cair em abstrações e arbitrariedades - de atravessar o abismo que separa a mente do pesquisador e o mundo pesquisado (JACKSON, 2011, p. 64). Por outros termos, como a mente do pesquisador (onde os conceitos são pensados) e o mundo real (onde os fatos concretos estão situados) são independentes e separados, o pensamento e o mundo concreto têm que ser ligados de alguma forma: o teste empírico de hipóteses é a ponte que faz essa conexão, permitindo que o conhecimento possa ser validado no mundo real. O segundo pressuposto dessa epistemologia causal é a assunção "fenomenalista" de que o objeto do conhecimento é limitado aos fenômenos e fatos que podem ser observados e mensurados pelo pesquisador (JACKSON, 2011, p. 37). São as condições impostas por essa combinação de pressupostos epistemológicos (dualismo e fenomenalismo) que criam a necessidade de desenvolver técnicas, métodos e protocolos sofisticados de observação, mensuração e experimentação dos fenômenos sociais, de tal forma que isto permita construir teorias que espelhem o mundo num grau tão elevado de fidelidade ao ponto de serem consideradas uma generalização ou uma lei.

Se essa é a abordagem científica predominante, Jackson (2011) recorre à filosofia da ciência para mostrar que o dualismo fenomenalista está longe de constituir a única perspectiva epistemológica capaz de levar ao conhecimento científico: o dualismo não é a única perspectiva através da qual se 
pode enxergar a relação entre a mente e o mundo e o fenomenalismo não é a única forma de enxergar a relação entre o conhecimento e a observação. Desse modo, enquanto a perspectiva dualista reflete a tradicional visão cartesiana de uma mente isolada e independente do mundo externo, existe uma perspectiva alternativa - a "monista" - que desafia essa visão, partindo da premissa de que o mundo e a mente não nomeiam entidades distintas e independente, mas se interpenetram e se constituem mutuamente. Conforme explica Fierke (2005, p. 7), é óbvio que o mundo material existe fora da mente do sujeito, mas o seu conhecimento não pode ser alcançado nesse estado de pureza. Por outros termos, o mundo e o sentido que ele assume são sempre constituídos dentro do processo de interação entre os sujeitos do conhecimento e entre esses sujeitos e os objetos do mundo. É essa mútua constituição entre a mente e o mundo que a perspectiva monista pretende destacar. Quanto à relação entre o conhecimento e a observação, é importante notar que, se de um lado a perspectiva fenomenalista parte da presunção empirista de que o objeto do conhecimento é limitado às coisas que podem ser observadas, medidas ou experimentadas, existe de outro lado uma perspectiva alternativa - a "transfactualista" - que presume que nem todo objeto do conhecimento é observável, só podendo ser conhecido através da interpretação (JACKSON, 2011, p. 35-36). Essas perspectivas epistemológicas sobre a relação mente-mundo e a relação conhecimento-observação, que determinam o modo como os pesquisadores conhecem o que conhecem, permitem que diferentes combinações possam ser efetuadas, levando a quatro abordagens ${ }^{10}$ distintas na produção de conhecimento científico, que Jackson (201 1, p. 33) chama de neopositivismo, realismo crítico, analiticismo e reflexividade (ver Quadro 1).

QUADRO 1 - Abordagens epistemológico-metodológicas da produção de conhecimento nas ciências sociais

\begin{tabular}{|c|c|c|c|}
\hline & \multicolumn{2}{|c|}{ Relação entre conhecimento e observação } \\
\hline & & Fenomenalismo & Transfactulismo \\
\hline \multirow{2}{*}{$\begin{array}{c}\text { Relação entre sujeito } \\
\text { conhecedor e objeto } \\
\text { do conhecimento }\end{array}$} & $\begin{array}{c}\text { Dualismo } \\
\text { mente-mundo }\end{array}$ & Neopositivismo & Realismo crítico \\
\hline & $\begin{array}{c}\text { Monismo } \\
\text { mente-mundo }\end{array}$ & Analiticismo & Reflexividade \\
\hline
\end{tabular}

Fonte: Jackson (2011, p. 37).

O neopositivismo, que surge da combinação entre dualismo e fenomenalismo, corresponde à abordagem científica dominante que tratamos na 
seção anterior e no início desta seção. A segunda abordagem da tipologia de Jackson - o realismo crítico - funda-se numa combinação epistemológica diferente. Embora siga a mesma premissa dualista dos neopositivistas (considerando que o mundo e a mente do investigador são independentes e que, por esta razão, a conexão entre pensamento e realidade depende de hipóteses que possam ser testadas empiricamente), o realismo crítico presume que nem todo objeto do conhecimento é observável ou mensurável, ainda que seja real (transfactualismo). O realismo crítico, portanto, mantem a dicotomia sujeito-objeto, mas estende os limites do conhecimento científico ao inobservável. Essa abordagem pode ser vista, por exemplo, no construtivismo convencional ${ }^{11}$ defendido por Wendt (1987), quando o autor argumenta que o conhecimento sobre a política internacional pode ser válido cientificamente sem, contudo, deixar de considerar que "as relações sociais que constituem os Estados enquanto Estados são potencialmente inobserváveis" e, por essa razão, "requerem uma compreensão não empirista da estrutura do sistema e da análise estrutural” (WENDT, 1987, p. 344).

A terceira abordagem - o analiticismo - surge da combinação epistemológica monismo-fenomenalismo. Dessa perspectiva, a teoria é uma construção mental do seu autor, que não pretende reproduzir a realidade tal como ela é, mas sim fornecer um guia para a compreensão da realidade e o ordenamento da experiência. Dessa perspectiva, o analiticismo parte da presunção monista de que as teorias e as mentes que as produzem estão ligadas ao mundo numa relação de continuidade (em oposição ao dualismo dos neopositivistas e dos realistas críticos). Para além disso, o analiticismo coloca a teoria a serviço do ordenamento da experiência empírica, o que indica uma perspectiva fenomenalista da relação entre o conhecimento e a observação. Para o analiticismo, portanto, a teoria não é um retrato da realidade, mas é um modelo abstrato que deve ser validado por sua utilidade (ou não) enquanto ferramenta de análise dos fenômenos do mundo. Considerando a sua perspectiva monista, que não vê uma separação entre a mente e o mundo, e considerando que a sua pretensão teórica não é prover uma reprodução fiel da realidade, não faz sentido pensar em hipóteses na abordagem analiticista (pois não há um mundo externo e independente contra o qual elas possam ser testadas) e em "falsificação" (pois a sua validade depende da sua utilidade como fermenta de análise e não da sua veracidade em retratar o mundo tal como ele é). A tipificação ideal da estrutura internacional proposta por Keneth Waltz e a teoria da securitização nos termos defendidos por Ole Wæver são exemplos de teorias analiticistas, onde os autores propõem constructos simplificados, reduzidos aos seus elementos essenciais, que pretendem servir como modelos de análise e não como teorias representativas da realidade (WALTZ, 1979; W EVER, 2009; 2011). 
A quarta abordagem - a reflexividade - é a mais radical entre todas elas, assumindo uma posição diametralmente oposta à do neopositivismo. A reflexividade rejeita o dualismo e o fenomenalismo, assumindo que o que sabemos é inseparável do lugar onde estamos quando produzimos conhecimento (monismo) e que a construção teórica pode ir além da evidência observável (transfactualismo). Para as abordagens reflexivistas, a teoria é concretamente impactada pela participação do investigador no seu contexto social, o que significa que a ciência não pode fugir ou se isolar das suas próprias condições sociais de produção (JACKSON, 2011, p. 173). Desse modo, a reflexividade assume a impossibilidade de manter a neutralidade na produção de conhecimento nas ciências sociais, procurando incorporar à produção científica a situação do investigador dentro do mundo investigado, e defende uma produção teórica que não se prende à experiência fenomenal, mas busca transcendê-la para revelar ocultações, silenciamentos e hierarquias nem sempre percebidas, assumindo um compromisso normativo com a transformação das estruturas opressoras da sociedade. Sem constituir uma agenda única e fechada, a reflexividade pode ser exemplificada por uma variedade de teorias sociais, como a teoria crítica, o pós-colonialismo, o feminismo, etc. Em função das suas premissas monistas/transfactualistas, a reflexividade não vê sentido no uso dos protocolos neopositivistas de validação em suas agendas de pesquisa (teste e falsificação de hipóteses, generalizações e previsões). Como não há um mundo empírico "lá fora", independente da mente do investigador e objetivamente observável, contra o qual as hipóteses possam ser testadas, a produção teórica reflexiva deve ser validada, em primeiro lugar, pela sua habilidade de provocar uma maior consciência e uma maior reflexão crítica não só por parte dos produtores do conhecimento, mas também do seu público destinatário, e em segundo lugar, pela sua capacidade de contribuição prática para atingir os propósitos transformativos da teoria (JACKSON, 2011, p. 197-198).

O que é importante observar com base nessa tipologia é que a produção de conhecimento nas ciências sociais é "irredutivelmente pluralista" (JACKSON, 2011, p. 189), capaz de ser articulada em pelo menos quatro variações metodológicas que, por sua vez, surgem da combinação de dois eixos epistemológicos centrais: o eixo dualista-monista e o eixo fenomenalista-transfactualista. Isto aponta para uma multiplicidade de combinações possíveis através das quais o pesquisador pode conhecer o seu objeto de estudo, indo muito além da perspectiva dualista-fenomenalista da abordagem neopositivista dominante. $\mathrm{O}$ grande mérito do esforço de tipificação de Jackson, portanto, é fornecer elementos para justificar a coexistência e a tolerância entre diferentes estratégias de produção teórica, todas elas comprometidas com o caráter científico da produção de conhecimento, permi- 
tindo, assim, superar o mito da supremacia do modelo de rigor herdado da tradição positivista.

Isto requer, obviamente, que se repense a noção tradicional de ciência. Se é importante considerar as diversas perspectivas epistemológicas que têm guiado a produção de conhecimento nas ciências sociais, é preciso buscar, conforme defende Jackson, uma compreensão mais aberta sobre o que se entende por conhecimento científico, a fim de abrigar o amplo leque de posições que têm disputado espaço nesse debate. Nesse sentido, seguindo as indicações de Max Weber, Jackson propõe uma definição mais alargada de ciência - como sendo a "ordenação refletida da realidade empírica através da aplicação criteriosa e rigorosa de um conjunto de conceitos e teorias" (2011, p. 192) -, destacando três elementos necessários a qualquer investigação que reivindique o estatuto de ciência: sistematização (entendida como uma linha clara e consistente entre os pressupostos e a conclusão); criticismo público (entendida como a abertura ao debate, aí incluindo não só a comunidade acadêmica, mas também o público envolvido com as práticas relacionadas ao conhecimento produzido); e conhecimento "mundano" (entendido como o vínculo do conhecimento com os problemas concretos do mundo). Dessa perspectiva, os quatro caminhos aqui apontados são capazes de produzir conhecimento científico válido, sendo tal validade entendida "de acordo com os padrões internos de cada metodologia” (JACKSON, 2011, p. 191) e não de acordo com um padrão de validação hegemônico e universal.

Com esse pluralismo, abre-se não só um espaço mais democrático e tolerante para a coexistência entre as diferentes possibilidades de produção de conhecimento científico, mas também um caminho para a uma base epistemológica mais diversificada e equilibrada que pode ser útil aos estudos de defesa. Ainda que algumas críticas tenham sido endereçadas ao trabalho de Jackson - principalmente relacionadas à sua opção preferencial pela filosofia da ciência, em vez das correntes e questões políticas que alimentam as Relações Internacionais; à sua classificação da Teoria da Política Internacional de Waltz dentro do analiticismo, em vez do neopositivismo; à sua visão de que as quatro abordagens são bem delimitadas e mutuamente excludentes, ao contrário da possibilidade de mescla e combinação metodológica defendida no ecletismo analítico de Katzenstein; e à sua opção por manter a tipologia dentro dos limites do conhecimento científico, deixando de fora aqueles que não se reconhecem dentro do rótulo de ciência, como os pós-estruturalistas por exemplo ${ }^{12}-$, não se pode deixar de notar, ao mesmo tempo, o amplo reconhecimento da qualidade do seu trabalho (premiado em 2013 pela Seção de Teoria da International Studies Association, ISA). E a grande qualidade, para os propósitos deste artigo, es- 
tá no caminho apontado por Jackson (2011, p. 39) no sentido de superar o isolamento metodológico, questionar a superioridade das posições neopositivistas e apresentar uma linguagem comum que permita aos acadêmicos avaliarem e trocarem ideias sobre as escolhas epistemológicas e metodológicas uns dos outros. Daí a opção deste artigo de estruturar a discussão epistemológica sem ancorá-la no mosaico pulverizado de escolas, correntes e comunidades envolvidas com os estudos de defesa, mas sim na filosofia da ciência. Com isto propõe-se criar, seguindo a esteira de Jackson, "um espaço conceptual comum" que possibilite aos pesquisadores concordarem ou discordarem "sobre as mesmas coisas ou pelo menos sobre coisas similares” (2011, p. 39), contribuindo assim para superar a compartimentação, a falta de transparência e as pretensões de superioridade e universalidade neopositivistas no âmbito do estudo científico da defesa no Brasil.

\section{VOLTANDO À QUESTÃO DE PARTIDA: COMO ESTUDAR A DEFESA?}

Quando se pensa na emergência da defesa como uma área de estudo que se quer distinguir do senso comum e da sua forte carga doutrinária e se institucionalizar como uma área autônoma de pesquisa e produção de conhecimento científico - é inevitável reconhecer aí um "problema de demarcação". Este texto tentou jogar uma luz sobre a dimensão epistemológica envolvida nesse problema. Nesse sentido, o artigo procurou reunir elementos para mostrar que a demarcação da defesa enquanto área de estudos requer, em primeiro lugar, uma separação entre o que é uma ciência da defesa e o que é uma doutrina da defesa e, em segundo lugar, um olhar mais abrangente e diversificado, dentro do espaço demarcado por uma ciência da defesa, sobre as posições epistemológicas possíveis para a produção de conhecimento cientificamente válido. A filosofia da ciência foi a base utilizada para encontrar os fundamentos para esse pluralismo epistemológico.

Com base neste panorama geral, o ponto crucial a destacar é que as tentativas de articulação entre os estudos de defesa e os estudos de estratégia (partindo do argumento de que o legado racionalista/neopositivista desse último é necessário e suficiente para conferir um estatuto de cientificidade ao primeiro) mostram uma perspectiva plausível, porém redutora, sobre o que é o conhecimento científico e sobre as posições epistemológicas possíveis para a produção de conhecimento válido nas ciências sociais. Isto não significa que a perspectiva neopositivista deva ser descartada; ao contrário, ela é uma posição legítima, capaz de oferecer um aparato metodológico sofisticado e útil aos pesquisadores interessados em analisar as questões da defesa dentro da sua materialidade, a partir de uma epistemologia causal explanatória. $\mathrm{O}$ que se contesta aqui são as pretensões de superioridade e 
neutralidade que possam eventualmente vir anexadas à essa perspectiva. Sobre esse aspecto, a posição deste artigo, com base nos desenvolvimentos contemporâneos observados na filosofia da ciência, é absolutamente contundente: não há nada de natural, essencial, fundamental e definitivo que justifique a superioridade das abordagens neopositivistas. Tal como a reflexividade, o realismo crítico e o analiticismo, a perspectiva neopositivista parte de assunções filosóficas sobre a posição do pesquisador que traem a sua presunção de neutralidade. Embora os neopositivistas critiquem as demais posições, principalmente as pós-positivistas, acusando-as de falta de neutralidade por adotarem assunções explícitas sobre a posição epistemológica do pesquisador, é preciso perceber que as posições neopositivistas falham em reconhecer que elas também fazem, de uma forma implícita, exatamente a mesma coisa: a separação entre a mente e o mundo e a limitação do conhecimento ao observável não passam de premissas sobre a posição do pesquisador, que refletem, igualmente, escolhas filosóficas fundacionais (JACKSON, 2011; SMITH, 2013, p. 9). É importante perceber, em suma, que todas as posições epistemológicas aqui examinadas, inclusive a que está na base da perspectiva neopositivista, partem de premissas filosóficas e que a opção por uma ou outra se funda numa escolha pessoal, numa preferência do pesquisador, sem que qualquer critério, anterior e superior, possa determinar a "veracidade" ou a maior "neutralidade" de uma premissa sobre a outra.

Essa discussão leva à constatação de que o estudo científico da defesa pode ser buscado não só através da epistemologia causal neopositivista onde importa explicar as dinâmicas da defesa através da distribuição das capacidades militares, formulando novas hipóteses ou derivando hipóteses a partir de teorias gerais já existentes (teoria da guerra, balança de poder, dilema de segurança, dissuasão, balanço ataque-defesa, realismo defensivo, realismo ofensivo, etc.) -, mas também através das três alternativas epistemológicas anteriormente examinadas. Da perspectiva analiticista, importa construir modelos de análise que sirvam de "lentes" para organizar a observação empírica das dinâmicas da defesa. A produção teórica, dessa perspectiva, não busca uma teoria geral que pretenda retratar a defesa tal como ela é, mas propõe construir modelos simplificados, reduzidos aos elementos centrais e nucleares dos processos ou dos fenômenos que eles pretendem iluminar. Como uma construção intelectual do seu autor, esse tipo de teoria não é testável e nem se altera em função dos dados empíricos, mas deve ser visto como uma moldura de análise, uma ferramenta que pode ser útil ou não, dependendo das questões ou das dinâmicas da defesa que ser analisar. A teoria da securitização, organizada em torno de um aparato conceptual minimalista e abstrato (um ator de securitização tentando convencer um 
público-alvo, através do discurso político, de que uma determinada ameaça coloca em perigo a sobrevivência de um determinado objeto e que, por essa razão, deve ser neutralizada através de medidas excepcionais, em geral o uso da força) é um típico exemplo de teoria analiticista, que serve de ferramenta de análise para guiar a compreensão dos processos discursivos que levam à emergência de ameaças dentro da agenda política da defesa. Passando para a perspectiva reflexivista, a defesa assume possibilidades de estudo completamente diferentes. A reflexividade assume explicitamente que a produção teórica é socialmente impactada pela posição do pesquisador e adota um compromisso com a identificação e a crítica das estruturas ou arranjos sociais que, devido a algum mecanismo ou fator causal, são considerados injustos. Dessa perspectiva, a erradicação desse mecanismo causal pode levar à transformação dessas estruturas ou arranjos sociais na direção de um estado de coisas mais justo. Essa assunção explícita sobre a posição epistemológica do pesquisador e o compromisso normativo com a transformação social abrem espaço para que a defesa seja estudada fora dos seus quadros de referência convencionais, a partir de uma perspectiva crítica/emancipatória. Isto permite não só questionar as estruturas burocráticas da defesa, mas também vislumbrar estruturas alternativas e dar visibilidade a arranjos repressivos, silenciadores e produtores de marginalizações. A agenda teórica feminista - com as suas preocupações de gênero e com os seus reflexos práticos na crescente inserção das mulheres nas atividades de defesa - talvez seja a ilustração mais emblemática de como a perspectiva reflexivista tem contribuições importantes para se pensar a defesa de uma forma mais inclusiva. Da perspectiva realista crítica, finalmente, é possível estudar a defesa de um ponto de vista construtivista convencional. Ao propor uma via média entre as perspectivas racionalistas e as reflexivistas, o realismo crítico introduz uma perspectiva epistemológica preocupada com o papel crucial da construção social de identidades no comportamento do Estado e de outros atores nacionais e subnacionais. Numa época marcada por conflitos identitários, étnicos e religiosos, não há como deixar de incluir nos estudos de defesa a dimensão construtivista indicada pelos realistas críticos.

O que é crucial compreender, para concluir este artigo, é que o paradigma estratégico-realista, com a explanação causal que resulta da sua posição epistemológica fundamental, continuará a ser confrontado por perspectivas epistemológicas alternativas sobre a produção de conhecimento científico. Os seus esforços de estabelecer leis gerais e previsões, já desafiados pelo desenlace da Guerra Fria, continuam a ser desafiados pela complexidade e pela variedade de atores, questões, causas, fatores e dinâmicas que influenciam a construção das agendas de defesa em diferentes localizações. 
Se a defesa nos EUA continua a ser fortemente determinada pela tradição estratégico-realista, não se pode dizer que o mesmo se aplica à construção da agenda de defesa do Brasil, onde os aspectos relacionados à identidade pacífica do país, às preocupações com a justiça social, com a desigualdade, com o desenvolvimento, com o meio ambiente, etc., são colocados lado a lado com as preocupações materiais relacionadas à capacitação do aparato militar. Ainda que isto possa parecer conceptualmente inconsistente do ponto de vista do paradigma estratégico-realista, é importante compreender que a defesa, assim como qualquer outra agenda política, é socialmente construída, assumindo contornos locais, historicamente situados, que fogem a qualquer tentativa de captura por teorias gerais com pretensões de universalidade. Ainda que o paradigma estratégico-realista continue a usar o passado e as evoluções do presente para readaptar as suas teorias, realimentar as suas previsões e manter-se como a perspectiva dominante sobre as questões de segurança internacional e de defesa nacional e coletiva, nada indica que as demais perspectivas venham a deixar de criticar e apontar os limites dessa perspectiva dominante, chamando a atenção para a necessidade de conhecer a construção de identidades, o papel dos atores subnacionais, as estruturas de dominação, os silenciamentos e as invisibilidades, bem como o papel das ideias e da cultura na construção social da defesa. Não existe nesse debate um ponto convergente e universal por uma razão muito simples: cada uma dessas perspectivas parte de ângulos distintos sobre como a defesa deve ser estudada. Por isto, quanto mais diversificadas forem as posições epistemológicas e os aparatos metodológicos à disposição dos estudos da defesa, melhor preparados estarão os estudantes e pesquisadores para a compreensão desse conjunto complexo de aspectos e dinâmicas que não se deixam subjugar por qualquer esforço de simplificação. Deste ângulo, o pluralismo epistemológico é mais do que um desenvolvimento desejável, é um desenvolvimento necessário no contexto da nascente área dos estudos de defesa no Brasil.

\section{REFERÊNCIAS}

AGIUS, C. Social construtivism. In: COLLINS, A. (Ed.). Contemporary security studies. Oxford: Oxford University Press, 2010, p. 49-68.

BUZAN, B.; HANSEN, L. The evolution of international security studies. Cambridge: Cambridge University Press, 2009.

DINIZ, E. Epistemologia, história e estudos estratégicos: Clausewitz versus Keegan. Contexto Internacional, v. 32, n. 1, p. 39-90, 2010. 
FIERKE, K. M. Diplomatic interventions: conflict and change in a globalizing world. Basingstoke: Palgrave, 2005.

JACKSON, P. T. The conduct of inquiry in international relations: philosophy of science and its implications for the study of world politics. Abingdon: Routledge, 2011.

KRAUSE, K.; WILLIAMS, M. C. From strategy to security: foundations of critical security studies". In: KRAUSE, K.; WILLIAMS, M. C. (Ed.). Critical security studies: concepts and cases. Minneapolis: University of Minnesota Press, 1997, p. 33-60.

LIMA, L. Worlding Brazil: intellectuals, identity and security. London: Routledge, 2015.

NETO, M. D. A configuração dos Estudos de Defesa. Revista Brasileira de Estudos de Defesa, n. 1, v. 1, p. 206-222, 2014.

OLIVEIRA, G. C. Para além da polarização racionalismo-reflexivismo nas Relações Internacionais: a tipologia metodológica de Patrick Jackson e o pluralismo metodológico em debate. Relações Internacionais, n. 42, p. 117-135, 2014.

OLIVEIRA, G. C. A segurança internacional nos Estudos de Estratégia e na Teoria da Securitização: uma abordagem comparativa ilustrada pelo caso da crise nuclear iraniana. Nação e Defesa, n. 140, p. 134-153, $2015 \mathrm{a}$.

OLIVEIRA, G. C. Resposta à recensão crítica de António Horta Fernandes. IDN Brief, p. 5-7, set. 2015b.

PINTO, J. R. de A.; ROCHA, A. J. R.; SILVA, R. D. (Ed.). Pensamento brasileiro sobre defesa e segurança - reflexões sobre defesa e segurança: uma estratégia para o Brasil. Vol. 1, 2,3 e 4. Brasília: Ministério da Defesa, 2004.

PROENÇA JR., D.; DINIZ, E.; RAZA, S. G. Guia de Estudos Estratégicos. Rio de Janeiro: Zahar, 1999.

PROENÇA JR., D. Contexto, ciência e desafios: o Brasil diante da defesa e segurança. In: PINTO, J. R. de A.; ROCHA, A. J. R.; SILVA, R. D. (Ed.). Pensamento brasileiro sobre defesa e segurança - reflexões sobre defesa e segurança: uma estratégia para o Brasil. Vol. 1. Brasília: Ministério da Defesa, 2004, p. 85-115.

PROENÇA JR., D.; DUARTE, É. E. Os Estudos Estratégicos como base reflexiva da Defesa Nacional. Revista Brasileira de Política Internacional, v.0, p. 29-46, 2007.

RAZA, S. G. Sistemática geral de projeto de força: relações internacionais, tecnologia e segurança. Tese de Doutorado. Rio de Janeiro: COPPE/UFRJ, 2000. 
RAZA, S. G. A questão da cientificidade nos Estudos de Defesa. Política Externa, v. 12 , p. $91-110,2004$.

REUS-SMIT, C. Beyond metatheory. European Journal of International Relations, n. 19 , v. 3, p. 589-608, 2013.

SHARP, G. National security through civilian-based defense. Omaha: Association for Transarmament Studies, 1985.

SMITH, S. Introduction. In: DUNE, T.; KURKI, M.; SMITH, S. (Ed.). International relations theories: discipline and diversity. Oxford: Oxford University Press, 2013, p. $1-13$.

W EVER, O. The sociology of a not so international discipline: american and european developments in international relations. International Organization, v. 52, n. 4, p. 687-727, 1998.

WÆVER, O. Waltz's theory of theory. International Relations, v. 23, n. 2, p. 215-217, 2009.

WÆEVR, O. Politics, security, theory. Security Dialogue, v. 42, n. 4-5, p. 465-480, 2011.

WALTZ, K. N. Theory of international politics. New York: McGraw-Hill, 1979.

WENDT, A. The agent-structure problem in international relations theory. International Organization, v. 41, n. 3, p. 335-370, 1987. 


\section{NOTAS}

1. Esta é uma expressão usual no domínio da filosofia da ciência, que se refere às questões envolvidas na definição de fronteiras entre o que é ciência e o que não pode ser considerado ciência (Jackson, 2011, p. 9-16).

2. Herdadas de um conjunto de referências clássicas mutuamente compartilhadas, como Tucídides, Maquiavel e Hobbes.

3. Seguindo Jackson (2011, p. 58), emprega-se o termo neopositivista em vez de positivista, por considerar que o último termo está historicamente situado no contexto particular do "Círculo de Viena dos positivistas lógicos" no início do século XX. Ainda que o neopositivismo continue a operar dentro da tradição positivista, ele incorpora os desenvolvimentos posteriores sobre "verificabilidade" e "falsificabilidade" propostos por Karl Popper, Kuhn e Lakatos.

4. Esse traço dominante no estudo das questões de defesa no Brasil será retomado na segunda seção do artigo.

5. Agradeço aqui a alguns colegas da UFRJ, especialmente à Adriana Aparecida Marques, pela troca de ideias durante o debate informal realizado no âmbito da graduação em Defesa e Gestão Estratégica Internacional, por ocasião da visita técnica realizada em 29/09/2015 por uma comitiva do Ministério da Defesa. Algumas ideias reproduzidas neste e no próximo parágrafo surgiram nesse debate.

6. Esses conceitos, desenvolvidos na agenda de pesquisa dos Estudos da Paz, podem ser definidos nos seguintes termos: a defesa com base em pessoal civil é uma política de "defesa por civis", em vez da tradicional "defesa por militares"; ela é uma forma de resistência civil que pode complementar os meios militares, ou substituí-los integralmente, para deter ou defender uma sociedade contra ataques externos. $\mathrm{O}$ transarmamento é o processo gradual de substituição dos meios militares convencionais ou dos sistemas de armas nucleares por um sistema de defesa com base em pessoal civil (SHARP, 1985, p. 47,52).

7. Ainda que esses autores não se refiram ao "problema da demarcação" através desses termos, na verdade é isto que eles pretendem: demarcar a fronteira entre o que pode e não pode ser considerado conhecimento científico nos estudos de defesa.

8. Metateorias são teorias que tomam outras teorias como seu objeto de estudo. Ou seja, são teorias sobre a teoria. Nas Relações Internacionais, conforme destaca Reus-Smit (2013, p. 592), a metateoria tem sido comumente vista num sentido mais específico, como um conjunto de assunções lógicas (ontologias e epistemologias) que estabelecem a priori as condições de possibilidade para a produção teórica. 
9. Esta seção tem por base a síntese da tipologia metodológica de Patrick Jackson feita por Oliveira (2014).

10. Jackson chama essas quatro abordagens de "metodologias". É importante notar, porém, que aquele autor entende a metodologia num nível estratégico, colocando-a no mesmo patamar das preocupações epistemológicas e ontológicas. Para Jackson, a metodologia tem mais a ver com a filosofia da ciência do que com as preocupações técnicas e práticas do método, relacionadas à operacionalização da pesquisa (2011, p. 25-32).

11. "Convencional" no sentido em que aceita alguns aspetos-chave da teoria sistêmica neorrealista, como a centralidade do Estado, por exemplo, e tenta ela própria constituir-se como uma teoria sistêmica alternativa, situada na via média entre o racionalismo e a reflexividade. Uma segunda vertente, chamada de construtivismo crítico, rejeita essa "via média" proposta pelo construtivismo convencional e assume uma perspectiva francamente pós-positivista sobre a construção social da realidade, colocando no centro de sua agenda de pesquisa o discurso, a linguagem, o sentido, e adotando uma posição crítica em relação às reivindicações de verdade e às relações de poder (ver AGIUS, 2010, p. 61).

12. Essas críticas, dirigidas a Jackson principalmente nos fóruns de debates realizados em 2010 pelo Qualitative $\mathcal{E}^{\circ}$ Multi-Method Research (v. 8, n. 1) e em 2013 pelo Millennium: Journal of International Studies (v. 41, n. 2), encontram-se sintetizadas e comentadas em maiores detalhes no artigo de Oliveira (2014, p. 126-133). 


\section{RESUMO}

Com base na filosofia da ciência, o artigo tem por objetivo avançar uma proposta epistemológica pluralista dos estudos de defesa que não só vá além do senso comum e da dimensão doutrinária da defesa, mas também vá além da perspectiva neopositivista que está na base do paradigma estratégico-realista dominante.

Palavras chave: Epistemologia; Estratégia; Estudos de Defesa; Filosofia da Ciência.

\section{ABSTRACT}

Based on the philosophy of science, this article aims to advance a pluralistic epistemological proposal of Defense Studies not only going beyond common sense and the doctrinal dimension of defense, but also going beyond the neo-positivist perspective that underpins the strategic-realist dominant paradigm.

Key-words: Epistemology; Strategy; Defense Studies; Philosophy of Science.

Recebido em: 22/02/2016. Aprovado para publicação em: 16/05/2016. 